\title{
Prevention of melanoma metastases in lungs of BAT treated and peptide immunized mice
}

\author{
MEORA FEINMESSER, ANNAT RAITER and BRITTA HARDY \\ Department of Pathology and Felsenstein Medical Research Center, Tel-Aviv University School of Medicine, \\ Rabin Medical Center, Beilinson Campus, Petah-Tikva, Israel
}

Received March 10, 2006; Accepted May 12, 2006

\begin{abstract}
BAT is an immune-modulatory monoclonal antibody that exhibits strong lymphocyte-mediated anti-tumor activity against a variety of murine and human tumors. Peptide $\mathrm{A}$ is a vaccine we have developed by screening a phage display peptide library on BAT monoclonal antibody. Anti-tumor activity was obtained in mice inoculated with B16 melanoma by either a single injection with BAT or immunization with peptide A. The aim of this study was to follow and compare histopathologically the process of prevention of melanoma metastases in lungs of treated and immunized mice. Mice were sacrificed on different days after tumor inoculation, their lungs were weighed and the number of metastases was counted. The lungs were then fixed in formalin, embedded in paraffin, and stained with hematoxylin and eosin. Histological examination of tumor inoculated mice on day 10 revealed the existence of microscopic melanoma lesions $(0.01-0.012 \mathrm{~mm})$ that increased gradually in number and size and on day 21 , most of the metastases were large and spanned entire lobes, from the pleura to the hilum, measuring up to $3.5 \mathrm{~mm}$ and coexisting with scattered, small metastases showing the same morphology and pattern of lung involvement. On day 24, the lungs of untreated mice were massively infiltrated by coalescing metastases replacing up to $50 \%$ of the lung tissue and measuring up to $7.0 \mathrm{~mm}$. The number of lung metastases and weight was dramatically decreased by a single injection of BAT monoclonal antibody ten days post tumor inoculation. The treated mice clearly had fewer and smaller metastases in different mice at the different days post tumor inoculation. On day 21 , there were few small metastases measuring up to $1.6 \mathrm{~mm}$ and on day 24 no lung metastases were detected in this group that appeared with a completely normal lung structure. Immunization with peptide A started one day post tumor inoculation and was compared to immunization with control peptide N. Fourteen days post tumor inoculation, mice
\end{abstract}

Correspondence to: Dr Britta Hardy, Felsenstein Medical Research Center, Rabin Medical Center, Beilinson Campus, Petah Tiqva 49100, Israel

E-mail: bhardy@post.tau.ac.il; bhardy@clalit.org.il

Key words: melanoma, BAT, immunized mice immunized with peptide A had only 1-2 metastases (0.012$0.076 \mathrm{~mm}$ ) and on day 24 ranged up to $2 \mathrm{~mm}$ compared to control immunized mice where the tumor developed up to 5$7 \mathrm{~mm}$. Foci of lung inflammation in both the untreated, treated or immunized mice were rare, small, and not preferentially associated with the lung metastases. They were composed mainly of small lymphocytes and a few macrophages. This study is the basis of histopathological understanding of metastases prevention in lungs of mice immunized or treated by BAT monoclonal antibody.

\section{Introduction}

Immunotherapy is applied in cancer diseases to modulate the immune system response to kill tumor cells. Several types of immunotherapy based on different humoral and cell-immunity factors are currently undergoing preclinical and clinical trials. One approach involves the use of monoclonal antibodies (1) that selectively bind to a specific determinant on T cells (2), thereby either initiating an activation pathway or inducing an inhibitory effect (3). Monoclonal antibodies against CD3/TCR receptors trigger the proliferation of $\mathrm{T}$ cells and increase their cytolytic activity $(4,5)$; antibodies against CTLA4 block its inhibitory effect on T cells $(6,7)$.

We have described BAT monoclonal antibody that stimulates murine and human peripheral blood T lymphocytes proliferation (8). In addition, a single intravenous injection of $10 \mu \mathrm{g}$ per mouse of BAT monoclonal antibody induced regression of murine tumors in the lungs of mice injected with various tumors such as B16 melanoma, Lewis lung carcinoma or methylcholanthrene-induced fibrosarcoma (9). BAT monoclonal antibody induced human tumors regression such as SK-28 melanoma in the lungs of SCID mice engrafted with human lymphocytes (5). The anti-tumor activity of BAT is mediated by its immune stimulatory properties, as was evident from adoptive transfer experiments, in which splenocytes from BAT-treated mice induced regression of tumors (9). However, BAT differs from other agonistic antibodies, such as anti-CD3 and anti-CTLA4 (7) in that its antitumor activity involves both $\mathrm{T}$ cells and natural killer cells. In our earlier work, we defined the primary stimulatory effect of BAT on $\mathrm{CD}^{+} \mathrm{T}$ cells and found that BAT stimulation of CD4 cells induced INF- $\gamma$ secretion (10). The murine BAT mAb was humanized and is now undergoing clinical trials in cancer patients. Recently we have identified two distinct peptides 

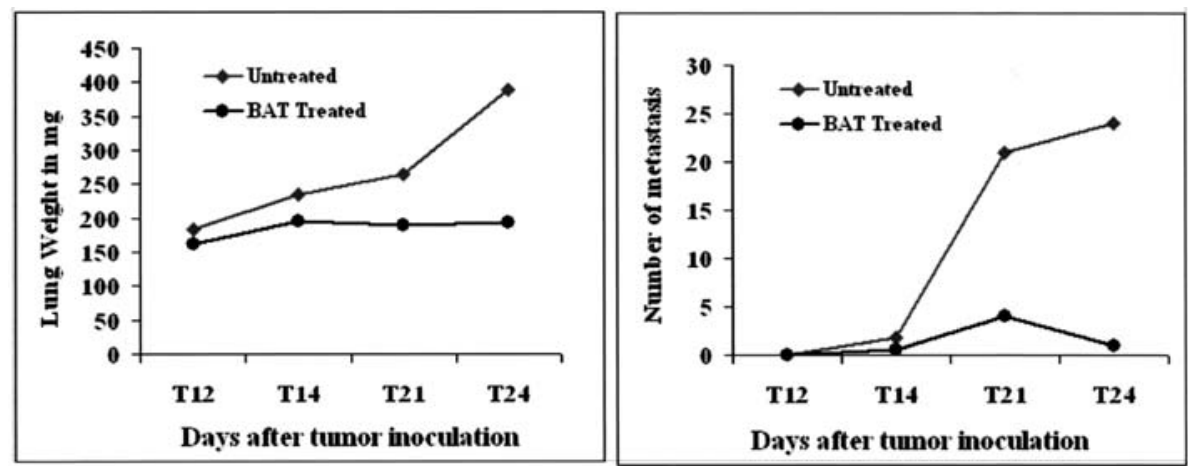

Figure 1. Macroscopic evaluation of lung weight and number of metastases of B16 melanoma in BAT-treated mice at different days. Mice injected with B16 melanoma and treated with a single administration of $10 \mu \mathrm{g}$ of BAT monoclonal antibody were sacrificed at different days after tumor inoculation. Lung weight was determined and number of melanoma metastases are represented.

from a phage display peptide library that bind BAT monoclonal antibody and induced upon immunization of mice cellular and humoral responses. The cellular response was manifested by a significant increase in cytolytic activity. The humoral response was manifested by the production of specific antibodies that competed with BAT binding. These 'BAT-like' antibodies exhibited immune stimulatory and anti-tumor properties (11).

The purpose of the present study was to follow histopathologically the process of melanoma metastasis growth in lungs of mice inoculated with B16 melanoma and the prevention of colonization of the tumor by either injection of BAT monoclonal antibody or by immunization with a BAT binding peptide.

\section{Materials and methods}

Mice inoculated with B16 melanoma and treated with BAT monoclonal antibody. C57BL mice were intravenously injected with $1.5 \times 10^{5} \mathrm{~B} 16$ melanoma cells in $0.250 \mathrm{ml}$ phosphatebuffered saline (PBS). Ten days later, one group of mice was injected intravenously with BAT monoclonal antibody in PBS (10 $\mu \mathrm{g} / \mathrm{mouse})$, and the second (control) group was injected with PBS only. At different times after tumor inoculation, two mice from each group were sacrificed. The lungs were removed and weighed, and the number of metastases was counted as previously described (9). At each time-point, the average weight of the lungs of the two mice sacrificed from each group was recorded. Metastases were scored by size from 1 (small) to 3 (large). Thereafter, the lungs were fixed in $10 \%$ buffered formalin and the tissues were embedded in paraffin. Six sections at increasing depths were stained with hematoxylin and eosin. The number of foci of inflammation was determined in 5 fields at magnification x100, regardless of whether they were associated with tumor or not. The number and maximum diameter of all the metastases in the sections were determined, as was their relation to the accompanying inflammatory infiltrates, if present. Results were compared by time and between groups.

Mice immunized with peptide A and inoculated with B16 melanoma. Immunization with peptides A (11) (Pro Arg Arg Ile Lys Pro Arg Lys Ile Met Leu Gln) was performed by injection of C57BL mice in the footpads with $10 \mu \mathrm{g}$ of peptide A mixed 1:1 in complete freund adjuvant (CFA) (Sigma, Israel).
Control mice were injected with PBS mixed with CFA. Boosters were given on days 7 and 14 after immunization by administration of $10 \mu \mathrm{g}$ of peptide in PBS in the footpads. Mice were injected with B16 melanoma cells $\left(0.18 \times 10^{6}\right.$ cells/mouse) intravenously 1 day after peptide immunization. At different times after tumor inoculation, two mice from each group were sacrificed. The lungs were removed and weighed and processed as described above.

\section{Results}

Macroscopic study. Macroscopic examination of B16 melanoma injected mice was evaluated by counting the number of metastases in the lungs and by lung weight. Mice revealed a marked, 2-fold increase in average lung weight from day $12(183 \mathrm{mg})$ to day $24(389 \mathrm{mg})$ reflecting an increase in tumor burden. Similarly, the mean number of lung metastases increased from 1.8 to 24 on day 24 . The number of lung metastases and weight was dramatically decreased by the single injection of BAT monoclonal antibody ten days post tumor inoculation (Fig. 1).

Light microscopy study of mice inoculated with B16 melanoma and treated with BAT monoclonal antibodies. Since macroscopically we did not identify melanoma lesions in lungs of mice 10 days post tumor inoculation, we performed histological examinations. Fig. 2 reveals at that time the existence of microscopic melanoma lesions that measured 0.01-0.012 mm. Four days later (on day 14 post tumor inoculation) the tumors grew and untreated mice had 3 and 5 lung metastases measuring 0.13-0.25 mm and 0.15-2.0 mm (Fig. 3A). However, mice injected with BAT monoclonal antibody 10 days post tumor inoculation revealed BAT antitumor effect as early as 4 days post treatment. The treated mice clearly had fewer and smaller metastases measuring between 0.1-0.2 $\mathrm{mm}$ in different mice as seen in Fig. 3B. In both the untreated and treated mice, foci of lung inflammation were rare, small, and not preferentially associated with the lung metastases. They were composed mainly of small lymphocytes, some with slightly irregular nuclei, and a few macrophages. The metastases contained a small number of scattered lymphocytes in equal amounts in the two groups. The exact number and size of the metastases and the number of foci of inflammation in all the mice examined are shown in Table I. 


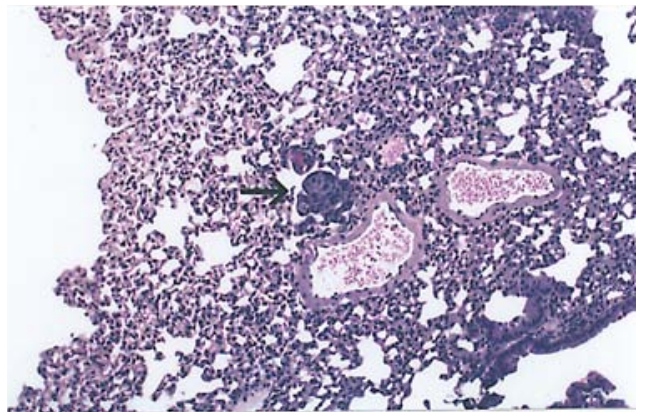

Figure 2. Lung of mouse 10 days post tumor inoculation demonstrates a microscopic metastasis in an interstitial location, close to a blood vessel. There are no accompanying lymphocytic infiltrates (x100).

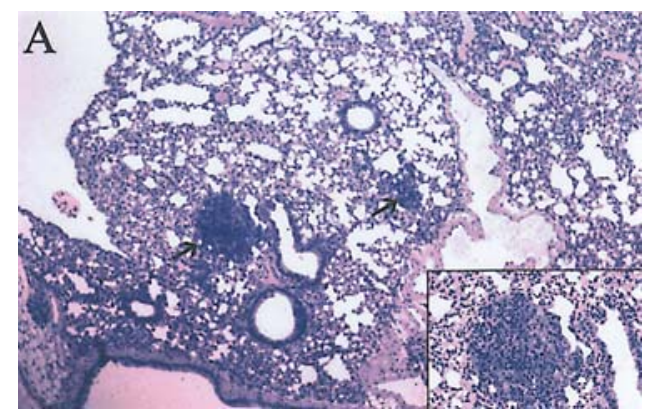

On day 21, the number of metastases in the untreated mice increased further, to 15 in one and 27 in the other, measuring 0.07-3.0 $\mathrm{mm}$ and 0.03-3.5 mm, respectively. Most of the metastases were large and spanned entire lobes, from the pleura to the hilum, even involving the mediastinal fat in one mouse. These coexisted with scattered, small metastases showing the same morphology and pattern of lung involvement. The two BAT treated mice had fewer metastases than the untreated mice, numbering 13 and 6 , and were clearly smaller, measuring 0.1-1.4 and 0.18-1.6 mm, respectively. Foci of inflammation were very sparse in both groups, and a few scattered lymphocytes extended focally into the tumors (Fig. 4).

Figure 3. Fourteen days after tumor inoculation the untreated mouse (A) has scattered small lung metastases (arrows) accompanied by a sparse lymphocytic infiltrate which also extends into the tumor (insert). In the BAT-treated mouse (B), there are fewer and smaller metastases (arrows), one of which is infiltrated by lymphocytes to a degree similar to that in the untreated mouse (insert) (x40, inserts x200).
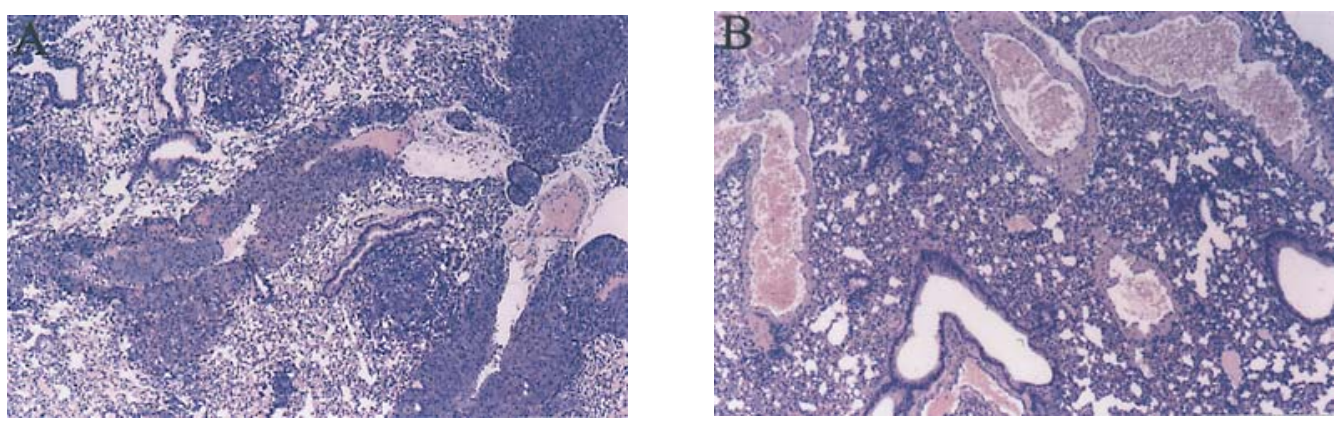

Figure 4. Twenty-one days after tumor inoculation the untreated mouse (A) shows numerous metastases within and around blood vessels as well as in the interstitium. There are no accompanying lymphocytic infiltrates. The lungs of the treated mouse (B) are negative for malignancy and show normal lung morphology (x40).
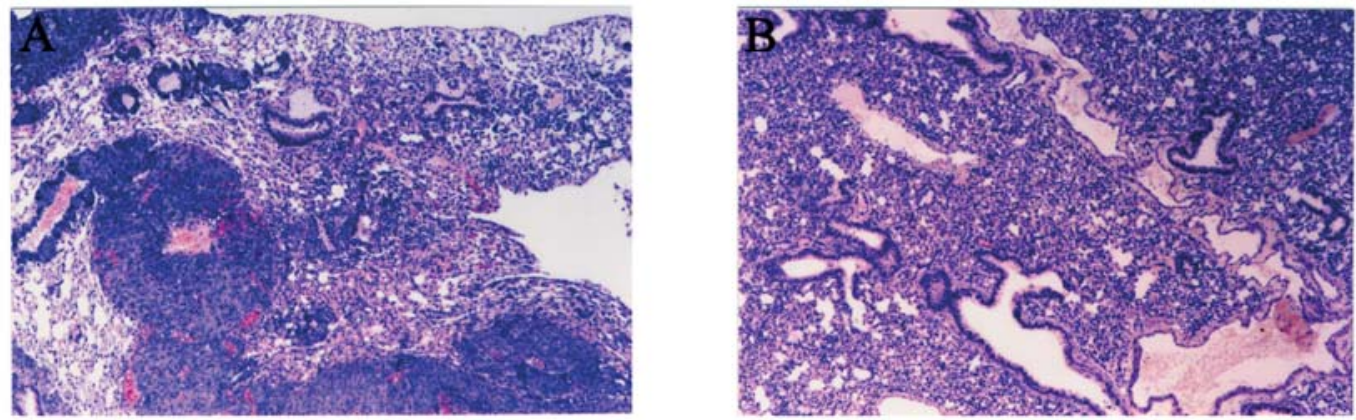

Figure 5. Twenty-four days after tumor inoculation in the untreated mouse (A), there are mainly large coalescing lung metastases, although the presence of minute lung metastases may be noted as well. There are no accompanying lymphocytic infiltrates. The lungs of the treated mouse (B) show no metastasis, and the lung structure is normal $(\mathrm{x} 40)$. 
Table I. Microscopic analysis of tumor metastases in the lungs of BAT treated mice.

\begin{tabular}{|c|c|c|c|c|c|c|}
\hline \multirow[b]{2}{*}{ Day } & \multicolumn{3}{|c|}{ Non-treated } & \multicolumn{3}{|c|}{ BAT treated } \\
\hline & $\begin{array}{l}\text { Number of } \\
\text { metastases }\end{array}$ & $\begin{array}{l}\text { Size } \\
(\mathrm{mm})\end{array}$ & $\begin{array}{c}\text { Inflammatory } \\
\text { infiltrates }\end{array}$ & $\begin{array}{l}\text { Number of } \\
\text { metastases }\end{array}$ & $\begin{array}{l}\text { Size } \\
(\mathrm{mm})\end{array}$ & $\begin{array}{c}\text { Inflammatory } \\
\text { infiltrates }\end{array}$ \\
\hline \multirow[t]{2}{*}{7} & 2 & $0.01-0.012$ & - & 1 & 0.012 & - \\
\hline & 2 & $0.008-0.01$ & - & 0 & 0 & - \\
\hline \multirow[t]{2}{*}{14} & 3 & $0.13-0.25$ & 2 & 3 & 0.1 & - \\
\hline & 5 & $0.15-2$ & 1 & 1 & 0.2 & 1 \\
\hline \multirow[t]{2}{*}{21} & 15 & $0.07-3$ & 1 & 13 & $0.1-1.4$ & 1 \\
\hline & 27 & $0.03-3.5$ & 1 & 6 & $0.18-1.6$ & 2 \\
\hline \multirow[t]{2}{*}{24} & 18 & $0.12-7$ & 0 & 0 & 0 & - \\
\hline & 13 & $0.03-3.5$ & 1 & 0 & 0 & 1 \\
\hline
\end{tabular}
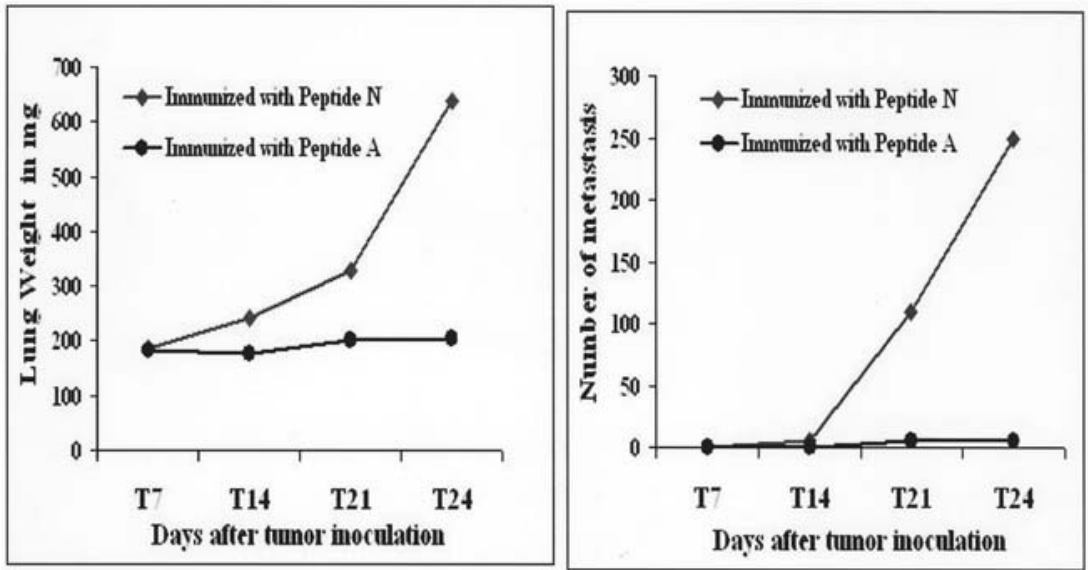

Figure 6. Macroscopic evaluation of lung weight and number of metastases in peptide A and control peptide $\mathrm{N}$ immunized mice injected with B16 melanoma. Mice were sacrificed at different days after tumor inoculation. Lung weight and the number of melanoma metastases were counted.

On day 24 , the lungs of the two untreated mice were massively infiltrated by coalescing metastases replacing approximately $50 \%$ and $30 \%$ of the lung tissue. Large and minute metastases coexisted. The metastases numbered 18 and 13 and measured $0.12-7.0$ and $0.03-3.5 \mathrm{~mm}$, respectively (Fig. 5A). The BAT treated mice examined that day had no lung metastases at all (Fig. 5B), and a completely normal lung structure. In both groups, inflammatory infiltrates were extremely sparse.

Since we have previously described (11) an anti-tumor vaccine prepared by immunization with peptides selected by BAT $\mathrm{mAb}$, that produce 'BAT-like' antibodies, we studied microscopically lungs of B16 melanoma inoculated mice immunized with such a peptide (peptide A) compared to the effect of immunized mice with a control non-relevant peptide (peptide $\mathrm{N}$ ).

Mice were immunized one day prior to tumor inoculation. As previously demonstrated immunization with peptide A induced a significant titer of specific BAT-like antibodies on day 14. Macroscopic examination of B16 melanoma injected mice was evaluated by counting the number of metastases in the lungs and by lung weight. As can be seen in Fig. 6, the average lung weight in control peptide $\mathrm{N}$ immunized mice increased from $187 \mathrm{mg}$ at day 7 to $638 \mathrm{mg}$ at day 24 and the number of metastases increased to 250 (confluent). Mice immunized with peptide A showed both a significantly lower lung weight and number of metastases. They had an average lung weight of $203 \mathrm{mg}$, and only 5.5 metastases counted at day 24 post tumor inoculation.

We followed by microscopic examination the lungs of the tumor inoculated immunized mice. Fourteen days post tumor inoculation, the lungs of control peptide $\mathrm{N}$ immunized mice revealed 4 and 6 lung metastases, respectively, measuring between $0.02-0.022 \mathrm{~mm}$ in one mouse and between 0.012 $0.076 \mathrm{~mm}$ in the second, whereas the two mice immunized with peptide A had only 1 metastasis (measuring $0.7 \mathrm{~mm}$ ) in 

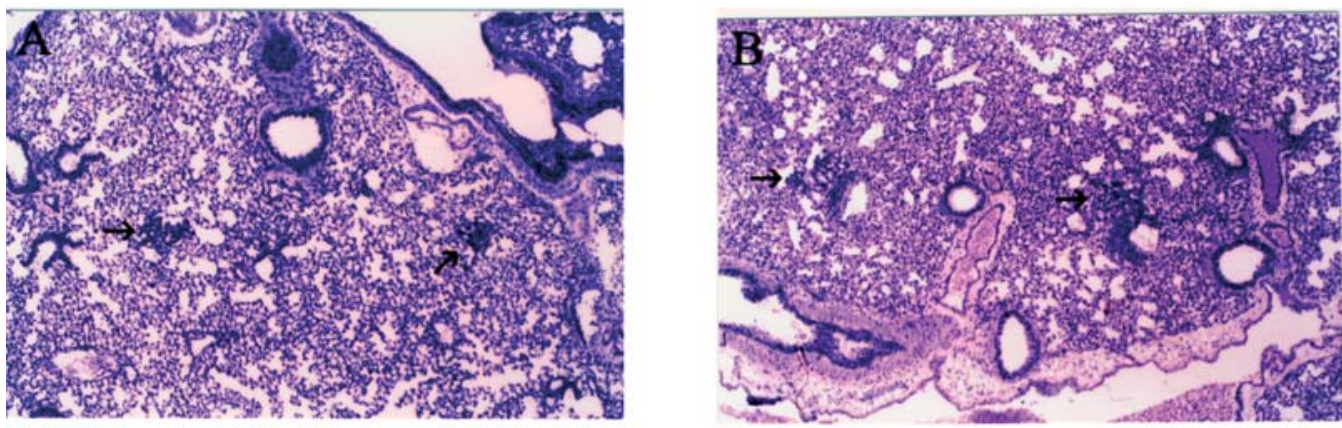

Figure 7. Fourteen days post tumor inoculation lungs of the immunized mouse with the control peptide $\mathrm{N}$, contains minute interstitial lung metastases (arrows). No lymphocytic infiltrates can be detected. The mouse immunized with peptide A (B) similarly shows small interstitial lung metastases which are devoid of lymphocytic infiltrates (x40).
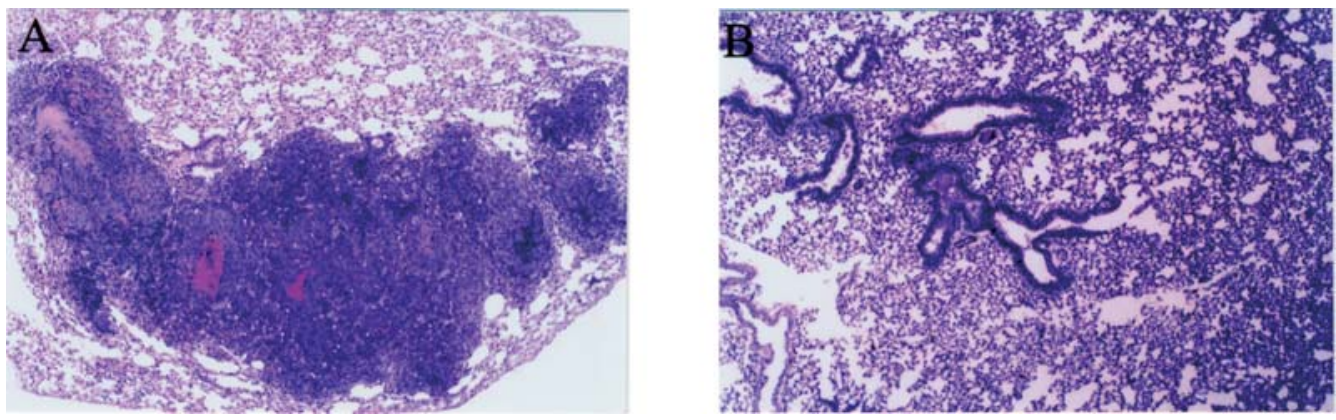

Figure 8. On day 21 post tumor inoculation, the lungs of mouse immunized with control peptide N, show a large metastasis which spans an entire lobe. No lymphocytic infiltrates are evident. The eosinophilic focus and densely basophilic foci represent different stages of tumor necrosis. In the peptide A immunized mouse (B) there are large expanses of normal lung tissue (x40).
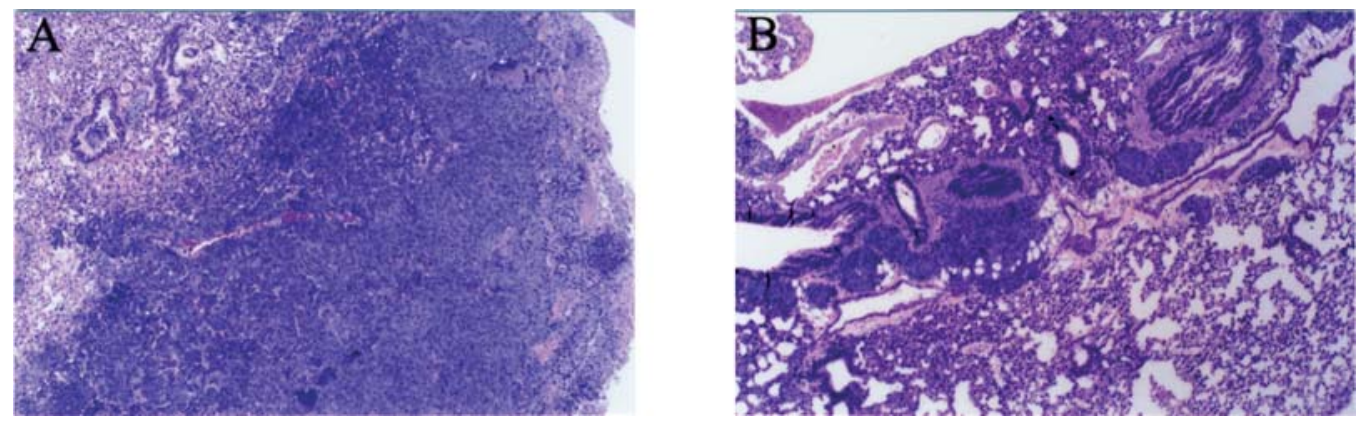

Figure 9. On day 24 post tumor inoculation the lungs of control peptide $\mathrm{N}$ immunized mice show massive metastases. Seen here (A) is a metastasis ranging from the pleura and replacing most of the lung parenchyma. No lymphocytic infiltrates are noted. In contrast, in the lungs of peptide A immunized mouse (B) the metastases are much smaller (x40).

one mouse and 2 metastases in the second mouse measuring 0.032 and $0.020 \mathrm{~mm}$ (Fig. 7).

Lungs of mice immunized with control peptide $\mathrm{N}$ and examined 21 days post-tumor inoculation demonstrated 12-13 metastases. The metastases ranged in size between $0.85-4 \mathrm{~mm}$ in one mouse and $0.47-3 \mathrm{~mm}$ in the second. Large areas of the lungs were involved, reaching up to about one-third of the pulmonary tissue. In contrast, in lungs of peptide A immunized mice were only 4 and 5 metastases, which were overall smaller, measuring between $0.12-1 \mathrm{~mm}$ and 0.06-1.5 mm (Fig. 8).
On day 24 post tumor inoculation, mice immunized with peptide $\mathrm{N}$ had 14-15 lung metastases. These ranged from minute to large, measuring between $0.06-7 \mathrm{~mm}$ and $0.25-5 \mathrm{~mm}$, respectively. The metastases involved large expanses of the lung tissue, replacing over half of the lung parenchyma. At this time the effect of peptide A immunization was most significant resulting in only one metastasis, measuring $1.5 \mathrm{~mm}$ in one mouse, and in the second, six small metastases ranging in size between 0.1-2 mm (Fig. 9). The exact number and size of the metastases and the number of foci of inflammation in all the immunized mice examined are shown in Table II. 
Table II. Microscopic analysis of tumor metastases in lungs of immunized mice.

\begin{tabular}{|c|c|c|c|c|c|c|}
\hline \multirow[b]{2}{*}{ Day } & \multicolumn{3}{|c|}{ Non-immunized } & \multicolumn{3}{|c|}{ Immunized } \\
\hline & $\begin{array}{l}\text { Number of } \\
\text { metastases }\end{array}$ & $\begin{array}{l}\text { Size } \\
(\mathrm{mm})\end{array}$ & $\begin{array}{l}\text { Inflammatory } \\
\text { infiltrates }\end{array}$ & $\begin{array}{l}\text { Number of } \\
\text { metastases }\end{array}$ & $\begin{array}{l}\text { Size } \\
(\mathrm{mm})\end{array}$ & $\begin{array}{c}\text { Inflammatory } \\
\text { infiltrates }\end{array}$ \\
\hline \multirow[t]{2}{*}{7} & 2 & $0.01-0.012$ & - & 1 & 0.012 & - \\
\hline & 2 & $0.008-0.01$ & - & 0 & 0 & - \\
\hline \multirow[t]{2}{*}{14} & 4 & $0.02-0.022$ & - & 1 & 0.7 & - \\
\hline & 6 & $0.012-0.076$ & 1 & 2 & $0.02-0.032$ & 1 \\
\hline \multirow[t]{2}{*}{21} & 13 & $0.85-4$ & - & 4 & $0.12-1$ & - \\
\hline & 12 & $0.47-3$ & - & 5 & $0.06-1.5$ & - \\
\hline \multirow[t]{2}{*}{24} & 15 & $0.06-7$ & 1 & 1 & 1.5 & 1 \\
\hline & 14 & $0.25-5$ & - & 6 & $0.5-2$ & - \\
\hline
\end{tabular}

\section{Discussion}

BAT contributes to the treatment of malignancies by its ability to stimulate the immune system and to induce antitumor activity mediated by lymphocyte populations. Previously, we examined antitumor activity by survival or by findings at termination of the study $(5,7,9,12)$. In the present work, we followed the longitudinal effects of BAT treatment, by examining tumor development histopathologically at different time-points. Moreover, we compared BAT monoclonal antibody treatment to immunization with peptide producing BAT-like antibodies. Microscopic examination of the lungs of untreated, BAT-treated and immunized mice injected with the B16 melanoma cells clearly demonstrated the efficiency of BAT antibody in reducing or eliminating malignant cells. The lag period between tumor injection and the identification of tumor foci in the lungs was approximately 10 days, when only small microscopic lung metastases were noted. From that point onwards, up to day 24 , there were clearly fewer and smaller metastases in the treated mice than in the untreated ones. In the peptide A immunized mice, metastases involved the same locations as described in the BAT-treated group. They were situated in interstitial, perivascular and subpleural locations.

The morphology of the metastatic lesions was similar in all groups, and was in accordance with earlier reports (13). The metastases were composed predominantly of epithelioid melanoma cells with vesicular nuclei, prominent nucleoli, and a moderate amount of occasionally pigmented eosinophilic cytoplasm. They tended to be situated along the visceral pleura, around blood vessels and bronchioles, and in an interstitial pattern within alveolar septa. These patterns were discernible so long as the metastases were small. The larger metastases were composed of sheets of cells extending from pleura to hilum and, in some cases, contained small foci of necrosis. Apoptosis was not evident. In all groups, the inflammatory infiltrates were few and small, whether associated with tumor or not. They were composed of mononuclear cells - lymphocytes and histocytes. The lymphocytes occasionally contained somewhat irregular nuclei, imparting an 'activated' appearance. When they accompanied metastases, the infiltrates were always located at one of the tumor poles; single lymphocytes extended into the tumor itself. The lungs of the successfully treated mice contained no evidence of tumor and appeared entirely normal. Treated tumors leave a variety of changes in their wake, including necrosis, fibrosis, and mixed or predominantly lymphohistiocytic infiltrates. In the case of treated pigmented melanomas, the macrophages also contain melanin. Therefore, the absence of evidence supporting the previous existence of tumor and the overall lack of significant inflammatory infiltrates in the treated mice suggest that the lungs are not the site at which BAT exerts its tumoricidal effects, but rather, they mirror BAT's success in eliminating tumor in the peripheral blood system. There is ample opportunity for BAT antibody to activate lymphocytes systemically as it travels through the lymphoreticular system. We previously demonstrated that lymphocytes obtained from mice injected with BAT exhibited an increase in thymidine uptake and increased cytolytic activity on tumor target cells (8). Thus, it is possible that BAT eliminates the malignant cells prior to their attachment to endothelium and extension into parenchymal organs. The metastases within the lungs following treatment represent tumor that has not been successfully eliminated in the blood system. The coexistence of large and minute lung metastases in both groups of mice may indicate that tumor cells circulate in the blood system continuously and that the lungs are showered by tumor emboli over time. Presumably, the larger metastases were implanted earlier. Alternatively, it is possible that the smaller metastases arise from the larger ones over time. In either case, BAT appears to eliminate or at least decrease the volume of tumor cells within the blood system, thereby limiting or entirely preventing the development of lung metastases. This also agrees with our earlier finding that in mice injected with BCL1 cells, BAT treatment reduced the number of tumor cells in the peripheral blood (14). It is possible that in high-risk melanoma patients (15-17) BAT may prevent the development of hematogenous metastases. 


\section{References}

1. Dickman S: Cancer therapy - antibodies stage a comeback in cancer treatment. Science 280: 1196-1197, 1998

2. Kohler G and Milstein C: Continuous cultures of fused cells secreting antibody of predefined specificity. Nature 256: 495-497, 1975.

3. Clark EA and Ledbetter JA: Amplification of the immune response by agonistic antibodies. Immunol Today 7: 267-269, 1986.

4. Meuer SC, Hussey RE, Contrell DA, Hodgson JC, Schlossman SF, Smith KA and Reinherz EL: Triggering of the T3-Ti antigenreceptor complex results in clonal $\mathrm{T}$ cell proliferation through an interleukin-2-dependent autocrine pathway. Proc Natl Acad Sci USA 81: 1509-1513, 1984.

5. Hardy B, Kovjazin R, Raiter A, Ganor N and Novogrodsky A: A lymphocyte-activating monoclonal antibody induces regression of human tumors in severe combined immunodeficient mice. Proc Natl Acad Sci USA 94: 5756-5760, 1997.

6. Schwartz RH: A cell culture model for T lymphocyte clonal anergy. Science 248: 1349-1356, 1990.

7. Raiter A, Novogrodsky A and Hardy B: Activation of lymphocytes by BAT and anti-CTLA4: comparison of binding to T and B cells. Immunol Lett 69: 247-251, 1999.

8. Hardy B, Galli M, Rivlin E. Goren L and Novogrodsky A: Activation of human lymphocytes by a monoclonal antibody to B lymphoblastoid cells; molecular weight and distribution of binding protein. Cancer Immunol Immunother 40: 376-382, 1995.
9. Hardy B, Yampolski I, Kovjazin R, Galli M and Novogrodsky A: A monoclonal antibody against a human B lymphoblastoid cell line induces tumor regression in mice. Cancer Res 54: 5793-5796, 1994.

10. Raiter A, Rodionov G, Novogrodsky A and Hardy B: CD4 ${ }^{+} \mathrm{T}$ lymphocytes as primary cellular target for BAT mAb stimulation. Int Immunol 12: 1623-1628, 2000.

11. Hardy B and Raiter A: A mimotope peptide-based anti-cancer vaccine. Vaccine 23: 4283-4291, 2005.

12. Hardy B, Kovjazin R, Raiter A, Ganor N and Novogrodsky A: Immune stimulatory and anti-tumor properties of anti-CD3 and BAT monoclonal antibodies: a comparative study. Hum Antibodies 8: 95-98, 1997.

13. Pili R, Guo Y, Chang J, Nakanishi H, Martin GR and Passaniti A: Altered angiogenesis underlying age-dependent changes in tumor growth. J Natl Cancer Inst 86: 1303-1314, 1994.

14. Hardy B, Indjiia L, Rodionov G, Raiter A and Inbal A: Treatment with BAT monoclonal antibody decreases tumor burden in a murine model of leukemia/lymphoma. Int J Oncol 19: 897-902, 2001.

15. Cochran AJ: Method of assessing prognosis in patients with malignant melanoma. Lancet 2: 1062-1064, 1968.

16. Sondergaard K and Schon G: Survival with primary cutaneous malignant melanoma, evaluated from 2012 cases. Virchows Arch (Pathol Anat) 406: 179-195, 1985.

17. Clark WH Jr, Elder DE, Guerry D, Braitman LE, Trock BJ, Schultz D, Synnestvedt M and Halpern AC: Model predicting survival in stage I melanoma based on tumor progression. J Natl Cancer Inst 81: 1893-1904, 1989. 